\title{
The effect of chromosome 17 polysomy on HER-2/neu status in breast cancer
}

C L Hyun, H E Lee, K S Kim, S-W Kim, J H Kim, G Choe and S Y Park

J. Clin. Pathol. 2008;61;317-321; originally published online 30 Aug 2007; doi:10.1136/jcp.2007.050336

Updated information and services can be found at:

http://jcp.bmj.com/cgi/content/full/61/3/317

These include:

References This article cites 29 articles, 15 of which can be accessed free at: http://jcp.bmj.com/cgi/content/full/61/3/317\#BIBL

2 online articles that cite this article can be accessed at:

http://jcp.bmj.com/cgi/content/full/61/3/317\#otherarticles

Rapid responses You can respond to this article at:

http://jcp.bmj.com/cgi/eletter-submit/61/3/317

Email alerting Receive free email alerts when new articles cite this article - sign up in the box at service the top right corner of the article

Notes

To order reprints of this article go to:

http://journals.bmj.com/cgi/reprintform

To subscribe to Journal of Clinical Pathology go to:

http://journals.bmj.com/subscriptions/ 


\title{
The effect of chromosome 17 polysomy on HER-2/neu status in breast cancer
}

\author{
C L Hyun, ${ }^{1}$ H E Lee, ${ }^{4}$ K S Kim, ${ }^{5}$ S-W Kim, ${ }^{2,5}$ J H Kim, ${ }^{3,6}$ G Choe, ${ }^{1,4}$ S Y Park ${ }^{1,4}$
}

${ }^{1}$ Department of Pathology, Seoul National University College of Medicine, Seoul, Korea; ${ }^{2}$ Department of Surgery, Seoul National University College of Medicine, Seoul, Korea; ${ }^{3}$ Department of Internal Medicine, Seoul National University College of Medicine Seoul, Korea; ${ }^{4}$ Department of Pathology, Seoul National University Bundang Hospital, Seongnam, Gyeonggi, Korea; ${ }^{5}$ Department of Surgery, Seoul National University Bundang Hospital, Seongnam, Gyeonggi, Korea; ${ }^{6}$ Department of Internal Medicine, Seoul National University Bundang Hospital, Seongnam, Gyeonggi, Korea

Correspondence to: Dr So Yeon Park, Department of Pathology, Seoul National University Bundang Hospital, 300 Gumi-dong, Bundang-gu, Seongnam-si, Gyeonggi-do, 463707, Korea; sypmd@snubh.org

Accepted 15 August 2007 Published Online First 30 August 2007

\section{ABSTRACT}

Aim: To investigate the effect of polysomy 17 on HER-2 status as evaluated by immunohistochemistry (IHC), dualcolour fluorescence in situ hybridisation (FISH) and chromogenic in situ hybridisation (CISH).

Methods: Dual-probe FISH and single-probe CISH were performed to detect HER-2 gene amplification, and IHC to detect HER-2 expression, on 309 invasive breast cancers. Results: Polysomy 17 was detected in $32.0 \%$ of the total number of breast cancers; it was detected in $12.3 \%$ of the IHC 0 or $1+$ cases, $42.8 \%$ of the IHC $2+$ cases and $66.0 \%$ of the IHC $3+$ cases $(p<0.001)$. In addition, there was a substantially higher rate of polysomy 17 in the $\mathrm{IHC}$ $2+$ or $3+$ /FISH-negative cases than in the IHC 0 or $1+$ cases $(40.8 \%$ vs $12.3 \% ; p<0.001)$. The FISH and CISH results were concordant in 299 cases $(96.8 \%)$. Of the 10 discordant cases, FISH suggested amplification in five with disomy 17 and one with monosomy 17, whereas $\mathrm{CISH}$ pointed to borderline copy numbers in each of these six cases. The remaining four cases had high polysomy 17; CISH, but not FISH, indicated amplification.

Conclusions: Results suggest that an increase of HER-2 gene copy number secondary to polysomy 17 leads to HER-2 overexpression in some IHC $2+/ 3+$ breast cancers, without gene amplification. The high level of concordance between FISH and CISH suggests that CISH is a valid alternative to FISH for assessing HER-2 gene amplification. However, cases in which CISH indicates the presence of borderline copy numbers or low levels of amplification may need FISH to rule out polysomy 17 and to determine HER-2 gene amplification status accurately.

Amplification of the human epidermal growth factor receptor-2 (HER-2) gene and/or overexpression of HER-2 protein has been identified in 20$30 \%$ of breast cancers and is associated with poor prognosis in both node-negative and node-positive breast cancers. ${ }^{1-3}$ Since the introduction of trastuzumab, a humanised monoclonal antibody against the extracellular portion of the HER-2 protein, assessment of HER-2 status has been standard practice in women with breast cancer in order to identify patients that are most likely to benefit from trastuzumab. ${ }^{45}$

Various methods are available to assess HER-2; these consist of assays to evaluate gene numbers, and assays to evaluate mRNA and protein levels. ${ }^{6}$ Most laboratories use immunohistochemistry (IHC) to quantify HER-2 protein, and fluorescence in situ hybridisation (FISH) as a test for HER-2 gene amplification. Comparative studies of IHC and FISH have yielded high rates of concordance. ${ }^{7-11}$ HER-2 protein overexpression is attributable to gene amplification in approximately $90 \%$ of cases. ${ }^{12}$ It has been suggested that in the remaining cases
HER-2 protein overexpression is due to an increase in HER-2 gene copy number secondary to chromosome 17 polysomy. However, an effect of chromosome 17 polysomy on the expression of HER-2 protein is not well established, and tests of this proposal have given conflicting results. ${ }^{13-19}$

Chromogenic in situ hybridisation (CISH), using a peroxidase-based chromogenic reaction, is a new method for assessing gene amplification status. ${ }^{20}$ CISH also determines the actual extent of HER-2 gene amplification and has greater potential for integration into diagnostic laboratories than FISH. The use of CISH permits the histology of the specimen to be assessed at the same time, and the signal remains stable for a long time. A number of studies have shown generally good concordance between FISH and CISH results. ${ }^{20-25}$ However, it is still a matter of debate whether CISH is as reliable as FISH for assessing HER-2 gene amplification, given certain limitations of CISH.

The PathVysion kit (Vysis, Downers Grove, Illinois, USA) for FISH uses a dual probe system that detects simultaneously the HER-2 gene and the chromosome 17 centromere, and defines HER-2 gene amplification to have taken place when the HER-2 gene copy number per CEP17 is $\geqslant 2$. Although dual-colour CISH has been described recently, ${ }^{26} \mathrm{CISH}$ generally does not take into account chromosome 17 copy number and yields absolute HER-2 gene copy numbers. However, chromosomal 17 polysomy occurs frequently in breast cancer $^{27}$ and may complicate the scoring of HER-2 amplification. Such changes in chromosome 17 copy number could therefore lead to discrepancies between the results of CISH and FISH.

We undertook this study to evaluate the influence of chromosome 17 polysomy on the results of IHC, FISH and CISH and to assess the use of CISH for identifying HER-2 gene amplification.

\section{MATERIALS AND METHODS \\ Samples and tissue array construction}

A total of 309 cases of invasive breast cancer were collected at Seoul National University Bundang Hospital from May 2003 to December 2005. The study was conducted in two parts. For validation of our techniques, 216 consecutive cases of breast cancer were studied. An additional 93 cases with weakly or moderately positive staining for HER-2 on IHC (1 to $2+$ and $2+)$ were selected to evaluate the effect of polysomy 17 on the HER-2 status, particularly in this group of breast cancers.

All specimens were fixed in 10\% neutral buffered formalin, embedded in paraffin wax, and stained with $H \& E$ for histological examination. 
Figure 1 High level human epidermal growth factor receptor-2 gene amplification shown by fluorescence in situ hybridisation $(A)$ and chromogenic in situ hybridisation (B).
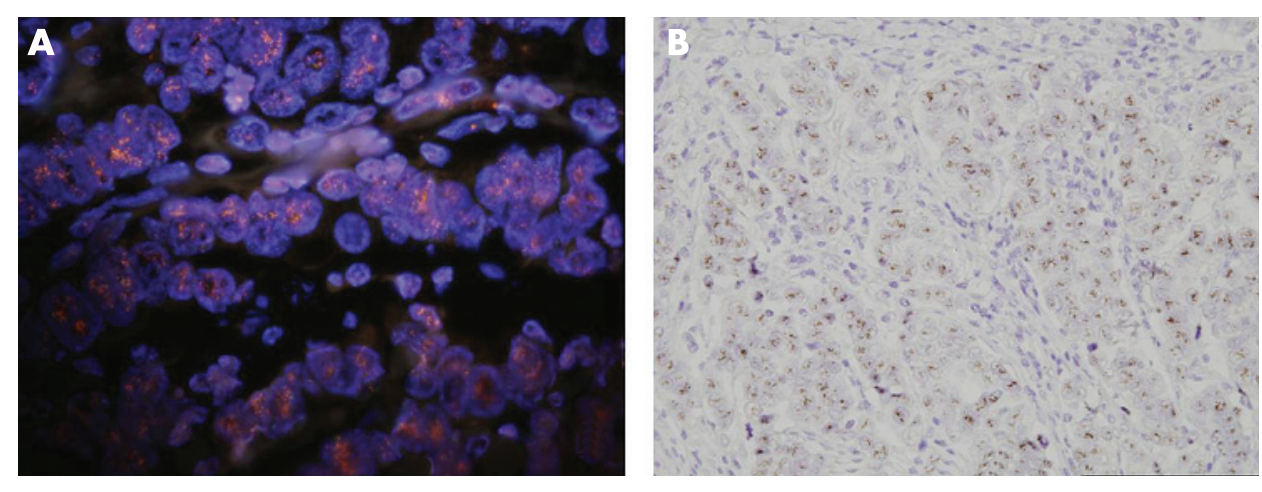

Tissue arrays were used for high throughput study as previously described. ${ }^{28}$ After screening the slides of each case, we selected a paraffin block that was well-fixed and contained a representative section of tumour. Three tissue columns $(2.0 \mathrm{~mm}$ each in diameter) were taken from each selected paraffin block and arranged in separate new paraffin blocks with 60 holes, using a trephine apparatus (Superbiochips Laboratories, Seoul, Korea). As an internal control, we inserted a tissue column from a normal breast or adenosis into two holes of each tissue microarray block.

\section{Immunohistochemical analysis}

Sections ( $4 \mu \mathrm{m}$ thick) of the tissue array block were cut, dried, deparaffinised and rehydrated as usual. For antigen retrieval, slides were places in a microwave in $0.1 \mathrm{M}$ citric acid at pH 7.2 for 15 minutes. Immunohistochemical staining was carried out in a DAKO Autostainer Plus (DakoCytomation, Glostrup, Denmark) using an LSAB detection kit (DakoCytomation). HER-2 protein was detected using polyclonal antibody A0485 (DakoCytomation) at a dilution of 1:700 with 40 minutes' incubation.

Expression was scored as follows: 0, no staining; 1+, weak and incomplete membranous staining in $\geqslant 10 \%$ of the tumour cells; $2+$, weak to moderate, complete membranous staining in $\geqslant 10 \%$ of the tumour cells; $3+$, strong, complete membranous staining in $\geqslant 10 \%$ of the tumour cells.

\section{FISH assays for HER-2 gene amplification}

The PathVysion (Vysis) assay was carried out with the protocol recommended by the manufacturer on $4 \mu \mathrm{m}$ sections prepared from the tissue array block. Sections were baked overnight at $56^{\circ} \mathrm{C}$, deparaffinised and dehydrated twice in xylene for 10 minutes, followed by immersion twice in $100 \%$ ethanol for 5 minutes. Air-dried slides were treated in a preheated $80^{\circ} \mathrm{C}$ pretreatment solution (Vysis) for 30 minutes, washed twice in $2 \times$ standard saline citrate (SSC) for 5 minutes each and then

Table 1 Comparison of IHC, FISH and CISH

\begin{tabular}{llll}
\hline & HER-2 IHC & \\
\cline { 2 - 4 } & $\begin{array}{l}\mathbf{0} \text { or } \mathbf{1 +} \\
(\mathbf{n}=\mathbf{1 4 6})\end{array}$ & $\begin{array}{l}\mathbf{2 +} \\
(\mathbf{n}=\mathbf{1 1 3})\end{array}$ & $\begin{array}{l}\mathbf{3}+ \\
(\mathbf{n}=\mathbf{5 0})\end{array}$ \\
\hline FISH $(+)$ & $0(0 \%)$ & $15(13.3 \%)^{*}$ & $45(90.0 \%) \dagger$ \\
$\mathrm{CISH}(+)$ & $0(0 \%)$ & $12(10.6 \%)^{*}$ & $46(92.0 \%) \dagger$
\end{tabular}

*Ten cases were assessed as amplified by both methods; seven cases were discordant.

$\uparrow$ Forty-four cases were assessed as amplified by both methods; three cases were discordant

IHC, immunohistochemistry; FISH, fluorescence in situ hybridisation; $\mathrm{CISH}_{\text {, }}$ chromogenic in situ hybridisation. treated in a protease solution for 20 minutes at $37^{\circ} \mathrm{C}$. After protease digestion, they were washed in $2 \times$ SSC, fixed in $10 \%$ buffered formalin for 10 minutes and washed twice in $2 \times$ SSC before denaturation and hybridisation. An aliquot of the dual colour probe HER-2 SpectrumOrange/CEP17 SpectrumGreen (Vysis) was added, and a coverslip was applied and sealed with rubber cement. The slides were placed on a preprogrammed HYBrite (Vysis) with the following settings: denaturation at $73^{\circ} \mathrm{C}$ for 5 minutes, and hybridisation at $37^{\circ} \mathrm{C}$ for 16 hours. After hybridisation, the rubber cement was removed, and the slides were immersed in $2 \times$ SSC with $0.3 \%$ Nonidet P-40 (NP$40)$ at room temperature for 5 minutes. They were then washed twice for 5 minutes with $2 \times \mathrm{SSC} / 0.3 \% \mathrm{NP}-40$, the first at $74^{\circ} \mathrm{C}$, the second at room temperature. After drying, the sections were counterstained with 4,6-diamidino-2-phenylindole dihydrochloride (DAPI; Vysis).

At least 60 cells were evaluated for each breast cancer specimen; the genetic variables were reported as: HER-2 gene copy number, chromosome 17 copy number and average HER-2 gene to chromosome 17 ratio. The HER-2 gene was considered to be amplified in tumours with average ratios $\geqslant 2$. A ratio of 2 or more and less than 5 was defined as low level amplification; 5 or more as high level amplification. The cut-off points for chromosome 17 copy number changes were adopted from Ma et $a l^{17}$ with modification. Specimens with signals in the range 1.25-2.25 were defined as having disomy 17. The other cases were considered to have aneusomy 17: monosomy $17(<1.25$ signals per cells), low polysomy $17(>2.25$ but $\leqslant 3.75$ signals per cell), or high polysomy 17 (>3.75 signals per cell).

\section{CISH assays for HER-2 gene amplification}

Sections ( $4 \mu \mathrm{m}$ thick) were prepared as for FISH. They were then incubated in SPOT-Light Heat Pretreatment Solution (Zymed, South San Francisco, California, USA) at $98 \sim 100^{\circ} \mathrm{C}$ for 15 minutes, washed with phosphate buffered saline (PBS) and digested with SPOT-Light Tissue Pretreatment Enzyme (Zymed) at room temperature for 10 minutes. They were then washed with PBS and dehydrated through a graded series of ethanol. An aliquot of digoxigenin-labelled HER-2 probe (Zymed) was applied to the slides, which were then coverslipped, sealed with rubber cement and placed on a preprogrammed HYBrite (Vysis) with the following setting: denaturation at $95^{\circ} \mathrm{C}$ for 5 minutes, and hybridisation at $37^{\circ} \mathrm{C}$ for 16 18 hours. After hybridisation, the rubber cement was removed, and the slides were immersed twice in $0.5 \times$ SSC for 5 minutes, the first at room temperature and the second at $73^{\circ} \mathrm{C}$. After washing with distilled water, they were immersed in absolute methanol with $3 \% \mathrm{H}_{2} \mathrm{O}_{2}$ for 10 minutes and incubated with CAS-Block (Zymed) for 30 minutes. 
Figure 2 A discordant case showing human epidermal growth factor receptor2 overexpression $(3+)$ by immunohistochemistry $(A)$ and exhibiting high polysomy 17 (B). This case was assessed as having high level amplification by chromogenic in situ hybridisation (C), but not by fluorescence in situ hybridisation (D) because of correcting for chromosome 17 number.
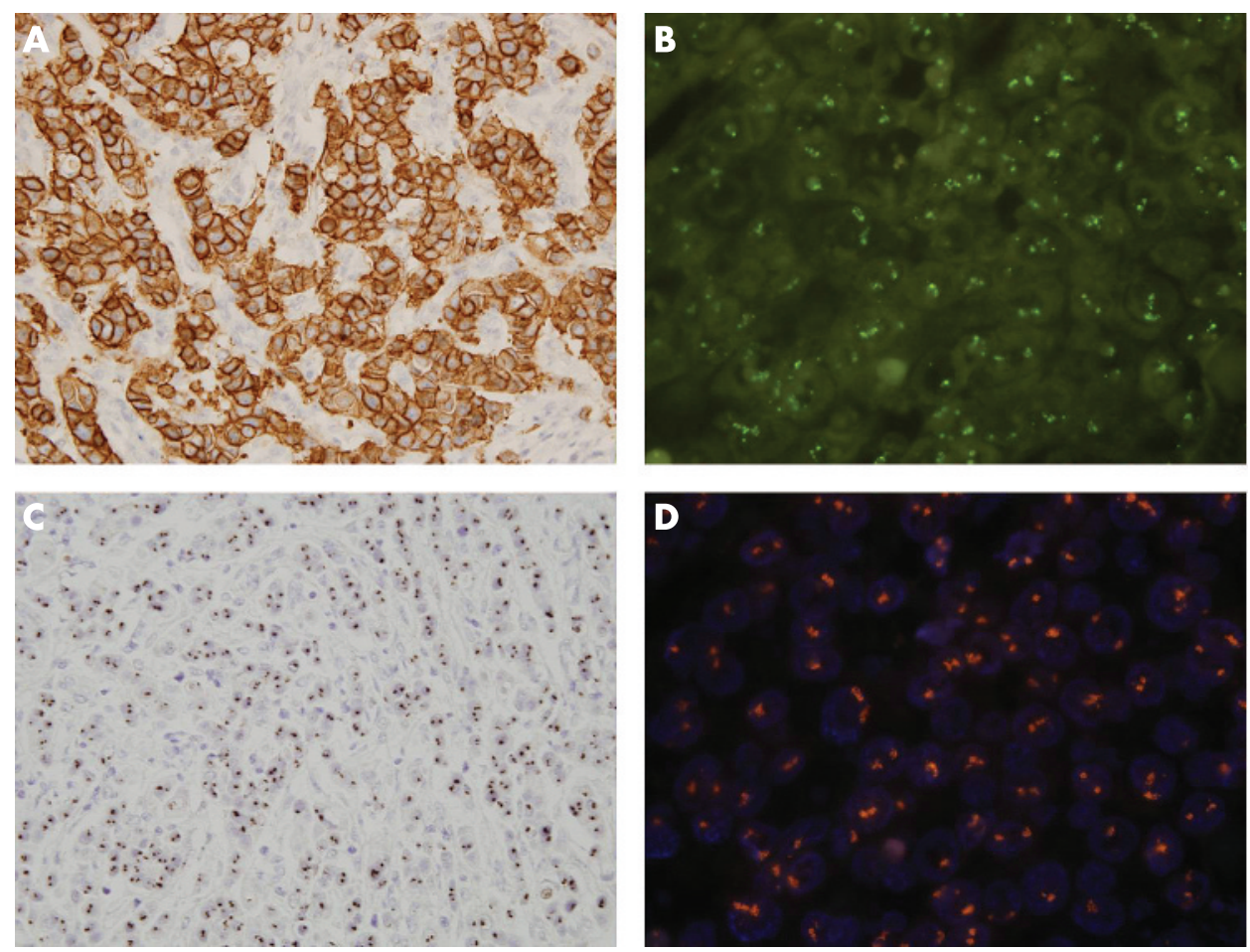

Hybridisation signals were detected after sequential incubations with mouse anti-digoxigenin (Zymed), polymerised horseradish peroxidase anti-mouse antibody and diaminobenzidine, according to the manufacturer's protocol (Zymed). The slides were counterstained with Mayer's haematoxylin (Zymed) for 3 minutes.

CISH results were evaluated by the criteria developed in a previous study. ${ }^{20}$ No amplification was defined as 1-5 signals per nucleus; low-level amplification as 6-10 signals, or as small signal clusters per nucleus, in $>50 \%$ of the tumour cells; and high-level amplification as $>10$ signals, or as large signal clusters, in $>50 \%$ of the tumour cells.

\section{Statistical analysis}

Statistical analyses were performed with SPSS software (V.11.0, SPSS Inc., Chicago, Illinois, USA). Incidences of polysomy 17 in relation to HER-2 IHC or FISH results were compared with the $\chi^{2}$ test or Fisher's exact test; $p<0.05$ was considered statistically significant. The degree of agreement between FISH and CISH was estimated by the Cohen $\kappa$ coefficient.

\section{RESULTS}

\section{Comparison of IHC with FISH and CISH}

We compared the results of HER-2 IHC and FISH in the 309 cases. FISH indicated that amplification was absent in all the 146 IHC 0 or $1+$ cases, and that amplification had taken place in $15(13.3 \%)$ of the 113 IHC $2+$ cases, and in $45(90.0 \%)$ of the 50 IHC $3+$ cases (table 1 ; fig $1 \mathrm{~A}$ ).

When we compared HER-2 IHC and CISH, we found that again amplification was absent in all the 146 IHC 0 or $1+$ cases. Amplification had occurred in $12(10.6 \%)$ of the IHC $2+$ cases, with 11 low level amplifications and one high level amplification. Of the IHC 3+ cases, 46 (92.0\%) were amplifications, with eight low level amplifications and 38 high level amplifications (table 1; fig 1B).

\section{Chromosome 17 polysomy in relation to IHC and FISH}

Using the criterion of $>2.25$ to define chromosome 17 polysomy, $32.0 \%$ (99/309) of the cases would be considered polysomic, with 81 cases $(26.2 \%)$ of low polysomy and 18 cases $(5.8 \%)$ of high polysomy. Four cases showed monosomy. The incidence of polysomy was $12.3 \%(18 / 146)$ among the IHC $0 / 1+$ cases, $42.8 \%$ (48/113) among the IHC $2+$ and $66.0 \%(33 / 50)$ among the IHC $3+$ cases $(p<0.001)$. In addition, whereas 42

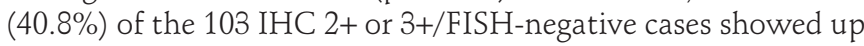
as polysomic, this was true of only $18(12.3 \%)$ of the 146 IHC 0 or $1+$ cases $(p<0.001)$. Polysomy 17 was found in $39(65.0 \%)$ of the 60 FISH-positive cases and 60 (24.1\%) of the 249 FISHnegative cases $(p<0.001)$.

\section{Comparison of FISH with CISH with regard to chromosome 17 copy number}

The results of FISH and CISH were discordant in 10 cases (table 2). Thus, concordance was $96.8 \%$ ( $\kappa$ coefficient, 0.917). Among the 10 discordant cases, five had disomy 17; amplification was revealed by FISH, but copy number (4-5 dots/nucleus) was borderline by CISH. Another discordant case had monosomy 17 and 3-4 HER-2 signals per cell. Thus it was assessed by FISH as having amplification, but not by CISH. The other four discordant cases had high polysomy 17, two with low level amplification by CISH, 5-7 CEP signals per cell and no amplification by FISH. The other two cases were $3+$ in IHC, with high level amplification by CISH, 8-14 CEP signals per cells and no amplification by FISH (fig 2).

\section{DISCUSSION}

We have investigated the effect of polysomy 17 on the expression of HER-2/neu protein as defined by IHC, and on the correlation between the HER-2/neu FISH and CISH tests. We found that an increase in HER-2 gene copy numbers resulting from polysomy 17 could lead to HER-2 protein overexpression in a subset of breast cancer in the absence of 
Table 2 Chromosome 17 copy number in cases discordant between FISH and CISH

\begin{tabular}{llll}
\hline $\begin{array}{l}\text { Chromosome 17 copy } \\
\text { number }\end{array}$ & No. of cases & FISH & CISH \\
\hline Disomy 17 & 5 & Low level amplification & No amplification (4-5 dots/nucleus) \\
Monosomy 17 & 1 & Low level amplification & No amplification (3-4 dots/nucleus) \\
High polysomy 17 & 4 & No amplification & Low or high level amplification* \\
\hline
\end{tabular}

*Two cases showed low level amplification by $\mathrm{CISH}$ and the others, high level amplification.

FISH, fluorescence in situ hybridisation; $\mathrm{CISH}$, chromogenic in situ hybridisation.

gene amplification. We also showed a high level of concordance between the HER-2 FISH and CISH tests and found that polysomy 17 contributed to the cases where the two tests disagreed.

In our study, polysomy 17 was present in $32.0 \%$ of the total cases, which is similar to the results reported by others. ${ }^{18}{ }^{21}$ The incidence of polysomy 17 in breast cancer has been reported to range from $10.3 \%$ to $48.7 \% .^{13-19}{ }^{27}$ The differences in reported incidence seem to depend on the criteria used to define polysomy, and the IHC status of the specimens used for analysis. Wang et $a l^{14}$ found polysomy 17 in as many as $48.7 \%$ of their cases, which were mostly IHC-positive.

Although the effect of chromosome 17 polysomy on the expression of HER-2 protein is not well established, it has been reported to be frequently associated with HER-2 protein overexpression, especially weak or moderate overexpression. ${ }^{13} 15-1719$ Merola et $a l^{19}$ found polysomy 17 in $46.1 \%$ of IHC $2+$ cases, which is similar to our result (42.8\%). We found that the incidence of polysomy 17 increased with IHC scores. Moreover, the IHC 2+ or 3+/FISH-negative cases had a significantly higher rate of polysomy 17 than the IHC 0 or $1+$ cases. These findings support the proposal that polysomy 17 contributes to HER-2 overexpression in cases without HER-2 amplification. Thus, polysomy 17 in the absence of HER-2 amplification seems to be associated with weak or moderate overexpression of HER-2 protein as a result of increased HER-2 gene copy number.

We noted that polysomy 17 was more frequent in the FISHpositive cases than in the FISH-negative cases; Lal et al ${ }^{15}$ reported a similar finding. In our cases, HER-2 gene amplification and polysomy 17 were associated with high grade carcinoma $(p<0.001$ and $p=0.039$, respectively; data not shown). Thus, the correlation between polysomy 17 and FISH-positivity may be explained by the high incidence of high grade carcinoma in those cases, as suggested by Lal et al. ${ }^{15}$

In our study there was excellent agreement between the $\mathrm{CISH}$ and FISH tests ( $\kappa$ coefficient, 0.917). This is consistent

\section{Take-home messages}

- Increased human epidermal growth factor receptor-2 (HER-2) gene copy numbers secondary to polysomy 17 may lead to HER-2 overexpression in some immunohistochemistry 2+/3+ breast cancers, without gene amplification.

- The high level of concordance between fluorescence in situ hybridisation (FISH) and chromogenic in situ hybridisation (CISH) suggests that $\mathrm{CISH}$ is a valid alternative to $\mathrm{FISH}$ for assessing HER-2 gene amplification.

- Cases in which CISH yields borderline copy numbers or low levels of amplification may need FISH to rule out polysomy 17 and to determine HER-2 gene amplification status accurately. with the results of previous studies. ${ }^{20-25}$ There was a discrepancy between CISH and FISH in 10 of our cases, most probably because of the difference in the scoring systems used in the two methods. The cut-off point for HER-2 amplification by CISH has been defined as six copies per cell, based on the observation that most cases with polysomy 17 fall into the category of 3-5 signals per nucleus. ${ }^{20}{ }^{23}$ However, polysomy with $>5$ copies of chromosome 17 per nucleus is not rare, ${ }^{23}$ and such cases may be scored as having low level amplification when there is actually no amplification. Two (10.5\%) of the 19 cases defined as having low level amplification by CISH turned out to have high levels of polysomy and thus no amplification by FISH. Forty-three of our cases had 3-5 HER-2 gene copies per nucleus by CISH and 37 of the cases involved polysomy 17 . However, five cases $(11.6 \%)$ had disomy 17 and were confirmed to have low level HER-2 amplification by FISH; the remaining case had monosomy 17 and was classified by FISH as having low level HER-2 amplification. Thus, a measure of chromosome 17 status is needed in cases with borderline copy number and low level amplification of HER-2 according to CISH, in order to confirm HER-2 gene amplification.

Among the discordant cases, two showed high level amplification by CISH but no amplification by FISH. However, these cases were IHC 3+ and had 10-26 HER-2 signals per cells. Isola et $a l^{23}$ also reported that two of their 12 cases of disagreement between CISH and dual-colour FISH had increased numbers of HER-2 copies (mean HER-2 copy numbers, 11.2 and 11.8), but were classified as no amplification by FISH because of correction for centromere number, despite the IHC $3+$ staining. However, they interpreted these as FISH false negatives. Recently, Hofmann et a ${ }^{29}$ reported that six of 26 metastatic breast cancer patients with polysomy 17 responded to trastuzumab; all six were IHC $3+$, and two were FISHnegative due to chromosome 17 polysomy. We think that cases with more than 10 HER-2 signals per cell should be regarded as FISH-positive, regardless of the HER-2 to CEP17 ratio. Thus, the absolute number of HER-2 signals should be considered in FISHnegative by dual probe system/IHC $3+$ cases.

In summary, an increase in HER-2 gene copy numbers due to polysomy 17 may lead to HER-2 protein overexpression in some IHC $2+/ 3+$ cases, without gene amplification. The high concordance between FISH and CISH suggests that CISH can be used as an alternative to FISH to assess HER-2 gene amplification. Polysomy 17 has an important effect on discrepancies between the two tests. Thus, cases with borderline copy numbers or low level amplification by CISH may require information on chromosome 17 status supplied by FISH for accurate determination of their HER-2 gene amplification status.

Funding: This work was supported by Seoul National University Bundang Hospital, Seongnam, Korea (Research Fund Grant No. 02-2004-016).

Competing interests: None declared. 


\section{REFERENCES}

1. Slamon DJ, Clark GM, Wong SG, et al. Human breast cancer: correlation of relapse and survival with amplification of the HER-2/neu oncogene. Science 1987;235:177-82.

2. Tandon AK, Clark GM, Chamness GC, et al. HER-2/neu oncogene protein and prognosis in breast cancer. J Clin Oncol 1989;7:1120-8.

3. Press MF, Pike MC, Chazin VR, et al. Her-2/neu expression in node-negative breast cancer: direct tissue quantitation by computerized image analysis and association of overexpression with increased risk of recurrent disease. Cancer Res 1993:53:4960-70.

4. Vogel CL, Cobleigh MA, Tripathy D, et al. Efficacy and safety of trastuzumab as a single agent in first-line treatment of HER2-overexpressing metastatic breast cancer. J Clin Oncol 2002;20:719-26.

5. Romond EH, Perez EA, Bryant J, et al. Trastuzumab plus adjuvant chemotherapy for operable HER2-positive breast cancer. N Engl J Med 2005;353:1673-84.

6. Slamon DJ, Godolphin W, Jones LA, et al. Studies of the HER-2/neu proto-oncogene in human breast and ovarian cancer. Science 1989;244:707-12.

7. Jacobs TW, Gown AM, Yaziji H, et al. Comparison of fluorescence in situ hybridization and immunohistochemistry for the evaluation of HER-2/neu in breast cancer. J Clin Oncol 1999:17:1974-82.

8. Couturier J, Vincent-Salomon A, Nicolas A, et al. Strong correlation between results of fluorescent in situ hybridization and immunohistochemistry for the assessment of the ERBB2 (HER-2/neu) gene status in breast carcinoma. Mod Pathol 2000;13:1238-43.

9. Lebeau A, Deimling D, Kaltz C, et al. Her-2/neu analysis in archival tissue samples of human breast cancer: comparison of immunohistochemistry and fluorescence in situ hybridization. J Clin Oncol 2001;19:354-63.

10. McCormick SR, Lillemoe TJ, Beneke J, et al. HER2 assessment by immunohistochemical analysis and fluorescence in situ hybridization: comparison of HercepTest and PathVysion commercial assays. Am J Clin Pathol 2002;117:935-43.

11. Yaziji H, Goldstein LC, Barry TS, et al. HER-2 testing in breast cancer using parallel tissue-based methods. JAMA 2004;291:1972-7.

12. Naber SP, Tsutsumi Y, Yin S, et al. Strategies for the analysis of oncogene overexpression. Studies of the neu oncogene in breast carcinoma. Am J Clin Pathol 1990;94:125-36

13. Bose S, Mohammed M, Shintaku P, et al. Her-2/neu gene amplification in low to moderately expressing breast cancers: possible role of chromosome 17/Her-2/neu polysomy. Breast J 2001;7:337-44.

14. Wang S, Hossein Saboorian M, Frenkel EP, et al. Aneusomy 17 in breast cancer: its role in HER-2/neu protein expression and implication for clinical assessment of HER-2/ neu status. Mod Pathol 2002;15:137-45.

15. Lal P, Salazar PA, Ladanyi M, et al. Impact of polysomy 17 on HER-2/neu immunohistochemistry in breast carcinomas without HER-2/neu gene amplification J Mol Diagn 2003:5:155-9.
16. Varshney D, Zhou YY, Geller SA, et al. Determination of HER-2 status and chromosome 17 polysomy in breast carcinomas comparing HercepTest and PathVysion FISH assay. Am J Clin Pathol 2004;121:70-7.

17. Ma Y, Lespagnard L, Durbecq V, et al. Polysomy 17 in HER-2/neu status elaboration in breast cancer: effect on daily practice. Clin Cancer Res 2005;11:4393-9.

18. Downs-Kelly E, Yoder BJ, Stoler M, et al. The influence of polysomy 17 on HER2 gene and protein expression in adenocarcinoma of the breast: a fluorescent in situ hybridization, immunohistochemical, and isotopic mRNA in situ hybridization study. Am J Surg Pathol 2005;29:1221-7.

19. Merola R, Mottolese M, Orlandi G, et al. Analysis of aneusomy level and HER-2 gene copy number and their effect on amplification rate in breast cancer specimens read as 2+ in immunohistochemical analysis. Eur J Cancer 2006;42:1501-6.

20. Tanner M, Gancberg D, Di Leo A, et al. Chromogenic in situ hybridization: a practical alternative for fluorescence in situ hybridization to detect HER-2/neu oncogene amplification in archival breast cancer samples. Am J Pathol 2000;157:1467-72.

21. Zhao J, Wu R, Au A, et al. Determination of HER2 gene amplification by chromogenic in situ hybridization (CISH) in archival breast carcinoma. Mod Pathol 2002;15:657-65.

22. Dandachi N, Dietze 0, Hauser-Kronberger C. Chromogenic in situ hybridization: a novel approach to a practical and sensitive method for the detection of HER2 oncogene in archival human breast carcinoma. Lab Invest 2002;82:1007-14.

23. Isola J, Tanner M, Forsyth A, et al. Interlaboratory comparison of HER-2 oncogene amplification as detected by chromogenic and fluorescence in situ hybridization. Clin Cancer Res 2004;10:4793-8.

24. Gong $\mathbf{Y}$, Gilcrease M, Sneige N. Reliability of chromogenic in situ hybridization for detecting HER-2 gene status in breast cancer: comparison with fluorescence in situ hybridization and assessment of interobserver reproducibility. Mod Pathol 2005;18:1015-21

25. Hanna WM, Kwok K. Chromogenic in-situ hybridization: a viable alternative to fluorescence in-situ hybridization in the HER2 testing algorithm. Mod Pathol 2006;19:481-7.

26. Laakso M, Tanner M, Isola J. Dual-colour chromogenic in situ hybridization for testing of HER-2 oncogene amplification in archival breast tumours. J Pathol 2006;210:3-9.

27. Watters AD, Going JJ, Cooke TG, et al. Chromosome 17 aneusomy is associated with poor prognostic factors in invasive breast carcinoma. Breast Cancer Res Treat 2003;77:109-14.

28. Park SY, Kim HS, Hong EK, et al. Expression of cytokeratins 7 and 20 in primary carcinomas of the stomach and colorectum and their value in the differential diagnosis of metastatic carcinomas to the ovary. Hum Pathol 2002;33:1078-85.

29. Hofmann M, Stoss 0, Gaiser T, et al. HER2 IHC and FISH analysis in a trastuzumab (Herceptin(R)) phase II monotherapy study: assessment of test sensitivity and impact of chromosome 17 polysomy. J Clin Pathol 2008;61:89-94.

Date for your diary

\author{
International Forum on Quality \& Safety in Health Care \\ 22-25 April 2008 \\ Le Palais de Congrès de Paris \\ Paris, France \\ http://www.internationalforum.bmj.com \\ Why attend? \\ - Join over 1000 healthcare professionals from over 40 countries worldwide \\ - Learn from experienced leaders and improvement experts \\ - Find out what is current in quality and safety \\ - Gain new skills and tools for creating change in your organisation \\ - Take home practical solutions for improvement methods \\ - Network with like-minded colleagues
}

This is a premier event for those dedicated to improving quality and safety in healthcare. Our focus is on practical, take-home ideas that will leave you inspired to implement valuable, lasting change on your return to the workplace.

Register online from January 2008 onwards

For more information on the forum visit - http://www.internationalforum.bmj.com 